\title{
Type 2 diabetes-associated genetic variants discovered in the recent genome-wide association studies are related to gestational diabetes mellitus in the Korean population
}

\author{
Y. M. Cho • T. H. Kim • S. Lim • S. H. Choi • \\ H. D. Shin $\cdot$ H. K. Lee $\cdot$ K. S. Park $\cdot$ H. C. Jang
}

Received: 21 July 2008 /Accepted: 10 October 2008/Published online: 11 November 2008

(C) Springer-Verlag 2008

\begin{abstract}
Aims/hypothesis New genetic variants associated with susceptibility to type 2 diabetes mellitus have been discovered in recent genome-wide association (GWA) studies. The aim of the present study was to examine the association between these diabetogenic variants and gestational diabetes mellitus (GDM).

Methods The study included 869 Korean women with GDM and 345 female and 287 male Korean non-diabetic controls. We genotyped the single nucleotide polymorphisms (SNPs) rs7756992 and rs7754840 in CDKAL1; rs564398, rs1333040,
\end{abstract}

Electronic supplementary material The online version of this article (doi:10.1007/s00125-008-1196-4) contains supplementary material, which is available to authorised users.

Y. M. Cho and T. H. Kim contributed equally to this study.

Y. M. Cho • T. H. Kim · S. Lim • S. H. Choi • H. K. Lee •

K. S. Park $(\bowtie) \cdot$ H. C. Jang

Department of Internal Medicine, College of Medicine,

Seoul National University,

28 Yongon-Dong Chongno-Gu,

Seoul 110-744, Korea

e-mail: kspark@snu.ac.kr

S. Lim $\cdot$ S. H. Choi $\cdot$ H. C. Jang $(\bowtie)$

Department of Internal Medicine, College of Medicine,

Seoul National University,

Seoul National University Bundang Hospital,

300 Gumi-dong, Bundang-gu,

Seongnam-City 463-707, Korea

e-mail: janghak@snu.ac.kr

H. D. Shin

Department of Life Science, Sogang University,

Seoul, Korea

H. D. Shin

Department of Genetic Epidemiology, SNP Genetics,

Seoul, Korea rs 10757278 and rs10811661 in the $C D K N 2 A-C D K N 2 B$ region; rs8050136 in FTO; rs1111875, rs5015480 and rs7923837 in HHEX; rs4402960 in IGF2BP2; and rs13266634 in SLC30A8. In addition, rs7903146 and rs 12255372 in TCF7L2; rs5215 and rs5219 in KCNJ11; and rs3856806 and rs1801282 in PPARG were genotyped. The genotype frequencies in the GDM patients were compared with those in the non-diabetic controls. Results Compared with controls (men and women combined), GDM was associated with rs7756992 and rs 7754840 (OR $1.55,95 \%$ CI $1.34-1.79, p=4.17 \times 10^{-9}$ ) in CDKAL1; rs10811661 (OR 1.49, 95\% CI 1.29-1.72, $p=1.05 \times 10^{-7}$ ) in the $C D K N 2 A-C D K N 2 B$ region; rs 1111875 (OR 1.27, 95\% CI $1.09-1.49, p=0.003)$, rs5015480, and rs7923837 in HHEX; rs4402960 (OR 1.18, 95\% CI 1.01-1.38, $p=0.03$ ) in IGF2BP2; rs13266634 (OR 1.24, 95\% CI 1.07-1.43, $p=0.005$ ) in SLC30A8; and rs7903146 (OR 1.58, 95\% CI $1.03-2.43, p=0.038)$ in TCF7L2. The risk alleles of the SNPs rs7756992 and rs7754840 in $C D K A L 1 ;$ rs10811661 in the $C D K N 2 A-C D K N 2 B$ region; and rs1111875, rs5015480 and rs7923837 in HHEX were associated with significant decreases in the insulin AUC during a $100 \mathrm{~g}$ OGTT performed at the time of diagnosis of GDM.

Conclusions/interpretation Some of the type 2 diabetesassociated genetic variants that were discovered in the recent GWA studies are also associated with GDM in Koreans.

Keywords Genetic association - Gestational diabetes mellitus · Type 2 diabetes

$\begin{array}{ll}\text { Abbreviations } \\ \text { CDK5 } & \text { cyclin-dependent kinase 5 } \\ \text { GDM } & \text { gestational diabetes mellitus } \\ \text { GWA } & \text { genome-wide association } \\ \text { HOMA-IR } & \begin{array}{l}\text { homeostasis model assessment of insulin } \\ \text { resistance }\end{array}\end{array}$




\section{KCNJ11 potassium inwardly rectifying channel, sub- family $\mathrm{J}$, member 11 \\ SNP single nucleotide polymorphism \\ TCF7L2 transcription factor 7-like 2}

\section{Introduction}

Gestational diabetes mellitus (GDM) - glucose intolerance of varying degrees of severity that is first recognised during pregnancy [1] -affects $2-14 \%$ of all pregnancies [2-4]. GDM may have the same genetic background as type 2 diabetes mellitus as there is evidence for the clustering of type 2 diabetes and impaired glucose tolerance in families with women with GDM [5] and for a higher prevalence of type 2 diabetes in mothers of women with GDM [6]. Furthermore, it is well known that women with GDM are at a greater risk of developing type 2 diabetes later in life [7-9]. However, knowledge regarding the genetics of GDM is limited [7, 10]. Several studies have examined candidate genes in women with and without GDM. Positive associations were shown for genes encoding glucokinase [11], calpain-10 [12], sulfonylurea receptor 1 [13], potassium inwardly rectifying channel, subfamily $\mathrm{J}$, member 11 (KCNJ11) [14], $\beta_{3}$ adrenergic receptor [15], plasminogen activator inhibitor 1 [16] and transcription factor 7-like 2 (TCF7L2) $[17,18]$. Except for the effects of TCF7L2 in Scandinavian women [17], no robust associations of genetic variants with GDM have been demonstrated.

In addition to those in KCNJ11, PPARG and TCF7L2, the recent genome-wide association (GWA) studies have identified new genetic variants with reproducible associations with susceptibility to type 2 diabetes [19-23], the majority of which were found in genes that were not even considered candidates [24]. Furthermore, robust signals $\left(p<5 \times 10^{-7}\right)$ were identified in certain gene regions (i.e. the $H H E X-I D E$ and $C D K N 2 A-C D K N 2 B$ regions) [19-23]. We recently found that the diabetogenic genetic variants reported by the large-scale GWA studies in Europids [1923 ] were also associated with the risk of type 2 diabetes in Asian populations, including Koreans [25].

If GDM and type 2 diabetes share a common genetic background, the genetic variants determining the risk of type 2 diabetes may also be associated with GDM. In the present study, we compared the genotype frequencies of the single nucleotide polymorphisms (SNPs) in the diabetogenic genes in GDM patients with those in non-diabetic controls.

\section{Methods}

Patients with GDM This study included 869 Korean women diagnosed with GDM at the Samsung Cheil
Hospital (Seoul, Korea) between January 1996 and February 2003. During the study period, 39,190 consecutive women underwent screening for GDM. We followed a previously described protocol for the screening and diagnosis of GDM $[3,26]$. In brief, all pregnant women without a previous diagnosis of glucose intolerance were screened for GDM between 24 and 28 weeks of gestation by using the $50 \mathrm{~g}, 1 \mathrm{~h}$ glucose challenge test as recommended by the Third International Workshop-Conference on GDM [1]. A plasma glucose concentration of $7.2 \mathrm{mmol} / \mathrm{l}$ or more was considered positive for GDM and was followed by a $100 \mathrm{~g}$ OGTT. GDM was diagnosed according to the criteria of the Third International Workshop-Conference on GDM [1]. The threshold glucose values were as follows: fasting $\geq 5.8 \mathrm{mmol} / \mathrm{l}, 1 \mathrm{~h} \geq 10.5 \mathrm{mmol} / \mathrm{l}, 2 \mathrm{~h} \geq 9.2 \mathrm{mmol} / \mathrm{l}$ and $3 \mathrm{~h} \geq 8.0 \mathrm{mmol} / \mathrm{l}$.

Gestational age at the time of the screening test was $27.9 \pm 2.9$ weeks (mean \pm SD). Plasma glucose concentration was measured by the glucose oxidase method using an YSI 2300 STAT analyser (Yellow Springs Instrument Company, Yellow Springs, OH, USA). Serum insulin concentration was measured using insulin-specific radioimmunoassay kits (Linco Research, St Louis, MO, USA). Homeostasis model assessment of insulin resistance (HOMA-IR) was calculated using the formula developed by Matthews et al. [27]. GAD antibodies were measured using a radioimmunoassay method (RSR, Cardiff, UK).

The clinical characteristics of women with GDM at 6 weeks postpartum are shown in Table 1 . Height and body weight were measured to the nearest $0.1 \mathrm{~cm}$ and $0.1 \mathrm{~kg}$, respectively, with the patient standing barefoot and in light clothing. BMI was calculated as body weight in kilograms divided by the square of height in metres. Blood pressure was measured after the participant had remained seated for 10 min. Measurements were taken twice, 5 min apart. The frequency of a positive family history of type 2 diabetes in women in the GDM group was $41.3 \%$. Women who tested positive for GAD antibodies were excluded from the study.

Non-diabetic controls We recruited 632 non-diabetic controls (345 women, 287 men) who visited Seoul National University Hospital for a routine health check-up. The following selection criteria were used: age $\geq 60$ years, no history of type 2 diabetes, no first-degree relatives with type 2 diabetes, fasting plasma glucose level $<6.1 \mathrm{mmol} / 1$ and $\mathrm{HbA}_{1 \mathrm{c}}$ level $<5.8 \%$. Therefore, controls were expected to be at a very low risk of type 2 diabetes. Table 1 shows the clinical characteristics of the controls in detail. It was not confirmed whether the non-diabetic female participants had experienced pregnancy without GDM. However, the ascertainment bias should be minimal given that the prevalence of GDM is estimated to be very low in Korea, at a rate of 2.2 cases per 100 pregnant women [3] 
Table 1 Clinical characteristics of the study participants

\begin{tabular}{|c|c|c|c|c|}
\hline & \multirow[t]{2}{*}{$\operatorname{GDM}^{\mathrm{a}}(n=869)$} & \multicolumn{3}{|c|}{ Non-diabetic controls } \\
\hline & & All $(n=632)$ & Men $(n=287)$ & Women $(n=345)$ \\
\hline Age (years) & $32.0 \pm 3.9$ & $64.7 \pm 3.6$ & $64.9 \pm 3.8$ & $64.4 \pm 3.3$ \\
\hline BMI $\left(\mathrm{kg} / \mathrm{m}^{2}\right)$ & $23.1 \pm 3.6$ & $23.3 \pm 3.0$ & $22.9 \pm 2.7$ & $23.9 \pm 3.3$ \\
\hline Systolic BP (mmHg) & $118 \pm 13$ & $128 \pm 20$ & $128 \pm 19$ & $129 \pm 20$ \\
\hline Diastolic BP (mmHg) & $73 \pm 9$ & $80 \pm 10$ & $81 \pm 11$ & $79 \pm 11$ \\
\hline Fasting plasma glucose $(\mathrm{mmol} / \mathrm{l})$ & $5.5 \pm 1.7$ & $4.9 \pm 8.7$ & $5.0 \pm 0.5$ & $4.9 \pm 0.5$ \\
\hline $\mathrm{HbA}_{1 \mathrm{c}}(\%)$ & NA & $5.3 \pm 0.3$ & $5.2 \pm 0.3$ & $5.3 \pm 0.3$ \\
\hline Total cholesterol (mmol/l) & $5.22 \pm 0.85$ & $4.98 \pm 0.90$ & $4.83 \pm 0.90$ & $5.10 \pm 0.88$ \\
\hline Triacylglycerol (mmol/l) & $3.89 \pm 2.68$ & $3.30 \pm 1.66$ & $3.22 \pm 1.63$ & $3.37 \pm 1.68$ \\
\hline HDL-cholesterol (mmol/l) & $1.37 \pm 0.33$ & $1.20 \pm 0.33$ & $1.21 \pm 0.35$ & $1.20 \pm 0.31$ \\
\hline LDL-cholesterol (mmol/l) & $3.09 \pm 0.70$ & $3.12 \pm 0.89$ & $2.98 \pm 0.91$ & $3.23 \pm 0.84$ \\
\hline Fasting plasma insulin (pmol/1) & $64 \pm 32$ & $47 \pm 29$ & $43 \pm 20$ & $51 \pm 35$ \\
\hline HOMA-IR & $2.6 \pm 1.5$ & $1.7 \pm 1.1$ & $1.6 \pm 0.8$ & $1.9 \pm 1.3$ \\
\hline
\end{tabular}

Data are presented as mean $\pm \mathrm{SD}$

${ }^{a}$ All values for the GDM group were measured at 6 weeks postpartum NA, not available

Ethical considerations The Institutional Review Board of the Clinical Research Institute of Seoul National University Hospital and the Research and Ethics Committee of the Samsung Cheil Hospital approved the study protocol, and informed consent was obtained from each study participant. The study was carried out in accordance with the principles of the Declaration of Helsinki as revised in 2000.

Gene and SNP selection SNPs from six novel genetic loci, which were identified through the recent GWA studies [1923] and showed reproducible associations with type 2 diabetes in Europeans, were selected for this study. Specifically, these were rs7756992 and rs7754840 in CDKAL1; rs564398 and rs 10811661 in $C D K N 2 A-C D K N 2 B$; rs8050136 in FTO; rs 1111875 , rs5015480 and rs7923837 in HHEX; rs4402960 in IGF2BP2; and rs13266634 in SLC30A8. Two representative SNPs (rs1333040 and rs10757278) close to $C D K N 2 A-C D K N 2 B$ that were associated with coronary heart disease and myocardial infarction were also selected [28-30]. In addition, rs7903146 and rs12255372 in TCF7L2 [31]; rs5215 and rs5219 in KCNJ11 [32]; and rs3856806 and rs1801282 in PPARG [33] were also genotyped.

Genotyping We genotyped 18 SNPs in nine genes from genomic DNA. An allelic discrimination assay was performed in $5 \mu$ of $1 \times$ TaqMan Universal PCR Master Mix (Applied Biosystems, Foster City, CA, USA) containing $20 \mathrm{ng}$ of genomic DNA and $0.125 \mu \mathrm{l}$ of $40 \times$ Assays-onDemand SNP genotyping product (Applied Biosystems), according to the manufacturer's instructions. (A list of the assay ID numbers and public ID numbers for the Assayson-Demand SNP genotyping products used in this study is presented in Electronic supplementary material [ESM]
Table 1.) Next, the plate was placed in a thermal cycler (PE 9700; Applied Biosystems) and heated for $2 \mathrm{~min}$ at $50^{\circ} \mathrm{C}$ and $10 \mathrm{~min}$ at $95^{\circ} \mathrm{C}$, followed by 40 cycles at $95^{\circ} \mathrm{C}$ for $15 \mathrm{~s}$ and $60^{\circ} \mathrm{C}$ for $1 \mathrm{~min}$. The TaqMan assay plate was then transferred to a Prism 7900HT instrument (Applied Biosystems) and the fluorescence intensity of each well was read. The fluorescence data files for each plate were analysed using Sequence Detection System version 2.1 (Applied Biosystems). Forty-four blind duplicates and eight blank samples were used as positive and negative controls, respectively. The overall genotyping success rate was 99.4\% (range 97.4-99.8\%; ESM Table 2) and the concordance rate based on blind duplicate comparisons was $99.6 \%$.

Statistical analyses All continuous variables are expressed as mean \pm SD. Statistical analyses were conducted using SPSS for Windows, version 11.0 (SPSS, Chicago, IL, USA). To determine whether individual polymorphisms were in Hardy-Weinberg equilibrium, $\chi^{2}$ tests were used. The result of the test for Hardy-Weinberg equilibrium and the statistical power for each variant are shown in ESM Table 2. Since there were no differences in the genotype frequencies between male and female non-diabetic controls (ESM Table 3), we initially compared the genotype frequencies of the 869 GDM patients with those of the 632 controls (i.e. both men and women), which was considered to be a non-diabetic gene pool. In addition, we compared the genotype frequencies of the 869 GDM patients with those of the 345 female controls. Logistic regression analyses were used for calculating the ORs, $95 \%$ CIs and the corresponding $p$ values with regard to the number of risk alleles using an additive model. Genotypes were given codes of 0,1 and 2, and the OR was expressed 
Table 2 Comparison of genotype frequencies between GDM patients and non-diabetic controls

\begin{tabular}{|c|c|c|c|c|c|c|c|}
\hline Gene & $\begin{array}{l}\text { Locus } \\
\text { (rs number) }\end{array}$ & $\begin{array}{l}\text { Allele } \\
\text { (major/minor) }\end{array}$ & Genotype & $\begin{array}{l}\text { GDM } \\
n(\%)\end{array}$ & $\begin{array}{l}\text { Control } \\
n(\%)\end{array}$ & OR $(95 \% \mathrm{CI})$ & $p$ value \\
\hline \multirow[t]{6}{*}{$C D K A L 1$} & \multirow[t]{3}{*}{ rs 7756992} & \multirow[t]{3}{*}{$\mathrm{G} / \mathrm{A}$} & AA & $145(17.1)$ & $137(21.7)$ & \multirow[t]{3}{*}{$1.39(1.20-1.61)$} & \multirow[t]{3}{*}{$9.14 \times 10^{-9}$} \\
\hline & & & GA & $374(44.0)$ & $325(51.4)$ & & \\
\hline & & & GG & $331(38.9)$ & $170(26.9)$ & & \\
\hline & \multirow[t]{3}{*}{ rs 7754840} & \multirow[t]{3}{*}{$\mathrm{C} / \mathrm{G}$} & GG & $171(19.8)$ & $178(28.3)$ & \multirow[t]{3}{*}{$1.55(1.34-1.79)$} & \multirow[t]{3}{*}{$4.17 \times 10^{-9}$} \\
\hline & & & $\mathrm{CG}$ & $389(45.1)$ & $319(50.6)$ & & \\
\hline & & & $\mathrm{CC}$ & $303(35.1)$ & $133(21.1)$ & & \\
\hline \multirow[t]{12}{*}{$C D K N 2 A / 2 B$} & \multirow[t]{3}{*}{ rs564398 } & \multirow[t]{3}{*}{$\mathrm{T} / \mathrm{C}$} & TT & $653(75.8)$ & $485(76.7)$ & \multirow[t]{3}{*}{$1.03(0.84-1.27)$} & \multirow[t]{3}{*}{0.78} \\
\hline & & & $\mathrm{CT}$ & $189(22.0)$ & $132(20.9)$ & & \\
\hline & & & $\mathrm{CC}$ & $19(2.2)$ & $15(2.4)$ & & \\
\hline & \multirow[t]{3}{*}{ rs 1333040} & \multirow[t]{3}{*}{$\mathrm{T} / \mathrm{C}$} & $\mathrm{TT}$ & $378(43.8)$ & $295(46.7)$ & \multirow[t]{3}{*}{$1.11(0.95-1.30)$} & \multirow[t]{3}{*}{0.20} \\
\hline & & & $\mathrm{CT}$ & $386(44.7)$ & $275(43.5)$ & & \\
\hline & & & $\mathrm{CC}$ & 99 (11.5) & $62(9.8)$ & & \\
\hline & rs 10757278 & $\mathrm{~A} / \mathrm{G}$ & $\mathrm{AA}$ & $238(28.4)$ & $183(29.3)$ & $1.05(0.91-1.22)$ & 0.50 \\
\hline & & & $\mathrm{AG}$ & $419(50.1)$ & $318(50.9)$ & & \\
\hline & & & GG & $180(21.5)$ & $124(19.8)$ & & \\
\hline & rs 10811661 & $\mathrm{~T} / \mathrm{C}$ & $\mathrm{CC}$ & $137(15.8)$ & $152(24.1)$ & $1.49(1.29-1.72)$ & $1.05 \times 10^{-7}$ \\
\hline & & & $\mathrm{CT}$ & $399(46.1)$ & $313(49.5)$ & & \\
\hline & & & $\mathrm{TT}$ & $330(38.1)$ & $167(26.4)$ & & \\
\hline FTO & rs8050136 & $\mathrm{C} / \mathrm{A}$ & $\mathrm{CC}$ & $643(74.4)$ & $486(77.3)$ & $1.12(0.90-1.40)$ & 0.30 \\
\hline & & & $\mathrm{AC}$ & $208(24.1)$ & $132(21.0)$ & & \\
\hline & & & AA & $13(1.5)$ & $11(1.7)$ & & \\
\hline HHEX & rs1111875 & $\mathrm{T} / \mathrm{C}$ & TT & $352(40.7)$ & $299(47.5)$ & $1.27(1.09-1.49)$ & 0.003 \\
\hline & & & $\mathrm{CT}$ & $413(47.6)$ & $278(44.1)$ & & \\
\hline & & & $\mathrm{CC}$ & $102(11.8)$ & $53(8.4)$ & & \\
\hline & rs5015480 & $\mathrm{T} / \mathrm{C}$ & $\mathrm{TT}$ & $525(60.9)$ & $416(65.8)$ & $1.22(1.01-1.47)$ & 0.035 \\
\hline & & & $\mathrm{CT}$ & $300(34.8)$ & $197(31.2)$ & & \\
\hline & & & $\mathrm{CC}$ & $37(4.3)$ & $19(3.0)$ & & \\
\hline & rs7923837 & $\mathrm{A} / \mathrm{G}$ & AA & $481(55.9)$ & $388(61.7)$ & $1.26(1.06-1.50)$ & 0.011 \\
\hline & & & $\mathrm{AG}$ & $329(38.3)$ & $218(34.7)$ & & \\
\hline & & & GG & $50(5.8)$ & $23(3.7)$ & & \\
\hline$I G F 2 B P 2$ & rs4402960 & $\mathrm{G} / \mathrm{T}$ & GG & $389(45.4)$ & $313(49.9)$ & $1.18(1.01-1.38)$ & 0.034 \\
\hline & & & GT & $365(42.6)$ & $257(41.0)$ & & \\
\hline & & & $\mathrm{TT}$ & $103(12.0)$ & $57(9.1)$ & & \\
\hline SLC $30 A 8$ & rs 13266634 & $\mathrm{C} / \mathrm{T}$ & $\mathrm{TT}$ & $126(14.6)$ & $107(17.1)$ & $1.24(1.07-1.43)$ & 0.005 \\
\hline & & & $\mathrm{CT}$ & $372(43.2)$ & $306(48.8)$ & & \\
\hline & & & $\mathrm{CC}$ & $363(42.2)$ & $214(34.1)$ & & \\
\hline TCF7L2 & rs7903146 & $\mathrm{C} / \mathrm{T}$ & $\mathrm{CC}$ & $803(95.2)$ & $596(95.1)$ & $1.58(1.03-2.43)$ & 0.038 \\
\hline & & & $\mathrm{CT}$ & $63(7.3)$ & $31(4.9)$ & & \\
\hline & & & $\mathrm{TT}$ & $2(0.2)$ & $0(0)$ & & \\
\hline & rs 12255372 & $\mathrm{G} / \mathrm{T}$ & GG & $860(99.2)$ & $628(99.7)$ & $2.56(0.53-12.34)$ & 0.24 \\
\hline & & & GT & $7(0.8)$ & $2(0.3)$ & & \\
\hline & & & $\mathrm{TT}$ & $0(0)$ & $0(0)$ & & \\
\hline KCNJ11 & rs 5215 & $\mathrm{~A} / \mathrm{G}$ & AA & $308(35.6)$ & $251(41.0)$ & $1.11(0.96-1.28)$ & 0.17 \\
\hline & & & $\mathrm{AG}$ & $416(48.1)$ & $260(42.5)$ & & \\
\hline & & & GG & $140(16.2)$ & $101(16.5)$ & & \\
\hline & rs5219 & $\mathrm{G} / \mathrm{A}$ & GG & $298(35.2)$ & $254(40.4)$ & $1.12(0.97-1.30)$ & 0.13 \\
\hline & & & $\mathrm{AG}$ & $407(48.1)$ & $273(43.4)$ & & \\
\hline & & & AA & $141(16.7)$ & $102(16.2)$ & & \\
\hline PPARG & rs3856806 & $\mathrm{C} / \mathrm{T}$ & TT & $28(3.2)$ & $22(3.5)$ & $1.09(0.90-1.32)$ & 0.37 \\
\hline & & & $\mathrm{CT}$ & $228(26.3)$ & $178(28.3)$ & & \\
\hline & & & $\mathrm{CC}$ & $612(70.5)$ & $430(68.3)$ & & \\
\hline & rs1801282 & $\mathrm{C} / \mathrm{G}$ & GG & $1(0.1)$ & $2(0.3)$ & $1.27(0.90-1.79)$ & 0.17 \\
\hline & & & $\mathrm{CG}$ & $71(8.2)$ & $63(10.0)$ & & \\
\hline & & & $\mathrm{CC}$ & $793(91.7)$ & $567(89.7)$ & & \\
\hline
\end{tabular}

$p$ values were not corrected for multiple comparisons 


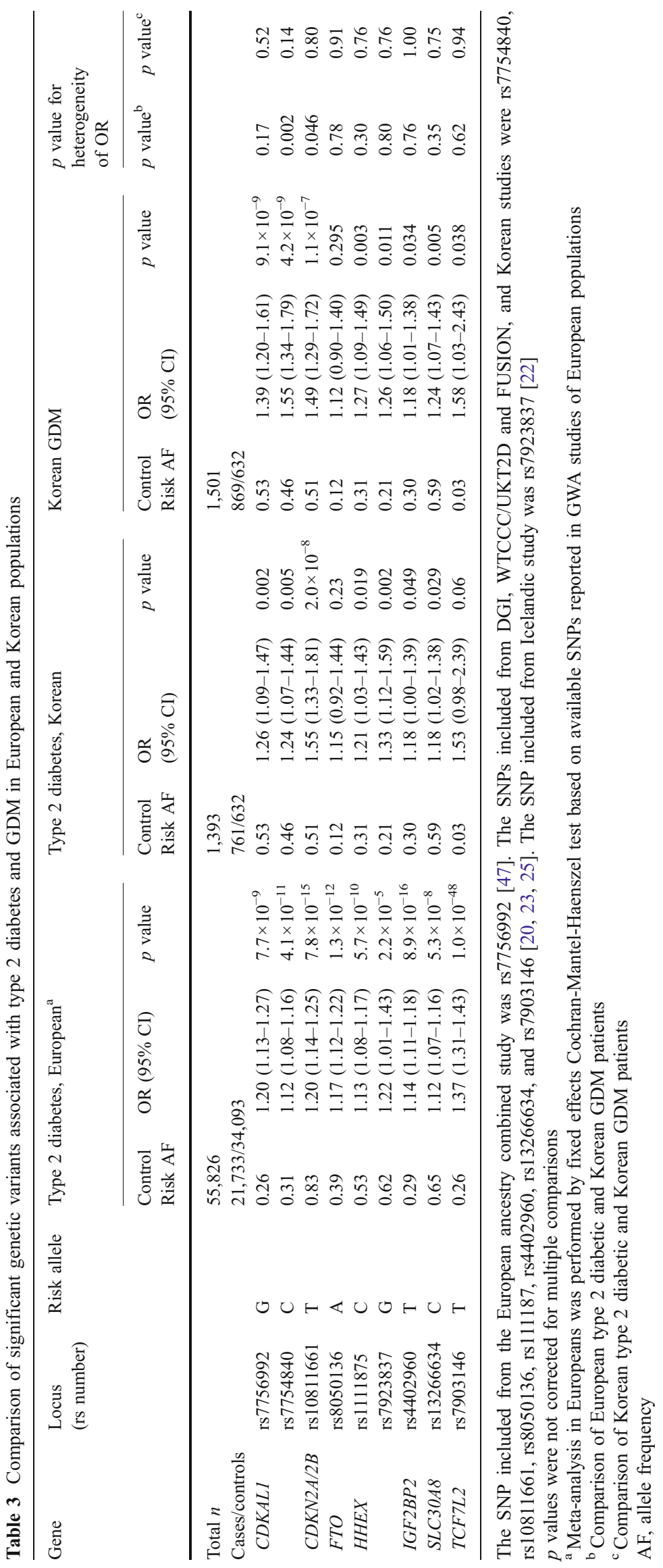


per difference in the number of risk alleles. For the comparison of representative SNPs for type 2 diabetes and GDM in European and Korean populations, the heterogeneity of ORs among studies or populations was assessed by Cochran's $Q$ statistic, as shown elsewhere [25]. Insulin resistance was evaluated using the HOMA-IR, and insulin secretory function was assessed by determination of the insulin AUC during a $100 \mathrm{~g}$ OGTT performed at the time of diagnosis of GDM. Multivariate linear regressions, adjusted for age and BMI, were used for comparing insulin resistance and insulin secretory function in GDM patients according to genotype. A $p$ value of less than 0.05 was considered statistically significant.

\section{Results}

We compared the genotype frequencies in the 869 GDM patients with those in the 632 non-diabetic controls (345 women, $287 \mathrm{men}$ ) who were expected to be at very low risk of type 2 diabetes. All SNPs were in Hardy-Weinberg equilibrium (ESM Table 2). Compared with the 632 controls, we found that GDM was significantly associated with rs7756992 $\left(p=9.14 \times 10^{-9}\right)$ and $\operatorname{rs} 7754840\left(p=4.17 \times 10^{-9}\right)$ in CDKAL1; $\operatorname{rs} 10811661\left(p=1.05 \times 10^{-7}\right)$ in CDKN2A$C D K N 2 B$; rs1111875 ( $p=0.003)$, rs5015480 $(p=0.035)$, and rs7923837 $(p=0.011)$ in HHEX; rs4402960 $(p=0.034)$ in IGF2BP2; rs13266634 $(p=0.005)$ in SLC 30A8; and rs7903146 $(p=0.038)$ in TCF7L2 (Table 2). In this analysis, three SNPs (rs7756992 and rs7754840 in CDKAL1 and rs10811661 in $C D K N 2 A-C D K N 2 B)$ met the stringent criterion for robust association $\left(p<5 \times 10^{-7}\right)$ [19], and their ORs ranged from 1.39 to 1.55 . When we compared the genotype frequencies in the GDM patients with those in the 345 female controls, rs7756992 $(p=0.001)$ and rs7754840 $\left(p=1.36 \times 10^{-5}\right)$ in $C D K A L 1 ; \operatorname{rs} 10811661\left(p=1.42 \times 10^{-7}\right)$ in $C D K N 2 A-C D K N 2 B$; and $\operatorname{rs} 13266634(p=0.044)$ in SLC30A8 showed significant associations with GDM (ESM Table 4).

Table 3 compares the ORs for the associations between the variants and GDM in our study with those previously reported for the associations of these variants with type 2 diabetes in European and Korean populations [20, 22, 23, 25, 47]. There were no significant differences in ORs between type 2 diabetes and GDM in Koreans. Although the effects on the risk of diabetes were in the same direction, the effect sizes of rs7754840 and rs10811661 were slightly greater for GDM in Koreans than for type 2 diabetes in Europeans.

Next, we examined the associations between the risk alleles and insulin resistance (i.e. HOMA-IR) and insulin secretory capacity (i.e. AUC of insulin during a $100 \mathrm{~g}$ OGTT; Table 4). No SNPs were significantly associated with HOMA-IR, with the exception of rs7754840 in CDKAL1 and rs1111875 in HHEX, which showed modest associations (adjusted $p=0.049$ and 0.026 , respectively). The risk alleles of the SNPs rs7756992 and rs7754840 in $C D K A L 1$ and rs10811661 in $C D K N 2 A-C D K N 2 B$, which, as mentioned above, showed robust associations with GDM, were associated with a marked decrease in AUC of insulin during a $100 \mathrm{~g}$ OGTT. Interestingly, the risk alleles of rs1111875, rs5015480 and rs7923837 in HHEX were also significantly associated with a reduced insulin AUC (adjusted $p=0.0000002,0.0002$, and 0.006 , respectively). In contrast, the risk allele of rs 8050136 in the FTO gene was associated with an increased AUC of insulin (adjusted $p=0.006$ ) but was not associated with HOMA-IR.

\section{Discussion}

We found that some of the SNPs recently identified as genetic determinants of type 2 diabetes by GWA studies [19-23] were also associated with GDM in Koreans. Three SNPs in particular (rs7756992 and rs 7754840 in CDKAL1 and rs10811661 in $C D K N 2 A-C D K N 2 B$ ) were very strongly associated with GDM. These same SNPs were significantly associated with insulin secretory capacity as assessed by the insulin AUC during a $100 \mathrm{~g}$ OGTT performed at the time of the diagnosis of GDM. However, they did not show any robust associations with insulin resistance. Their association with pancreatic beta cell function is consistent with the results obtained in a study on type 2 diabetes in the Japanese population, which showed that risk alleles at CDKAL1 (rs7756992) and CDKN2A-CDKN2B (rs10811661) were associated with impaired beta cell function [34].

It is well known that normal pregnancy is accompanied by a marked increase in insulin resistance, which may be the result of both increased maternal adiposity and the insulin-antagonising effects of several placental hormones [7]. Therefore, maternal pancreatic beta cell compensation is crucial for overcoming the insulin resistance provoked by pregnancy and for maintaining the metabolic balance during pregnancy. It has recently been shown that prolactin represses islet menin levels and stimulates beta cell proliferation during pregnancy in mice. It was found that the transgenic expression of the gene encoding menin in maternal beta cells inhibited islet expansion and led to the development of GDM phenotypes [35]. In human studies, inadequate compensatory insulin secretion in the face of increased insulin resistance has consistently been observed in patients with GDM [36-38]. In this regard, the risk alleles of rs7756992 and rs7754840 in $C D K A L 1$ and rs10811661 in $C D K N 2 A-C D K N 2 B$ may play crucial roles in the pathogenesis of GDM through impaired compensatory insulin secretion by pancreatic beta cells. 
Table 4 Associations between risk alleles and insulin resistance and insulin secretory function

\begin{tabular}{|c|c|c|c|c|c|c|c|c|}
\hline Parameter & Gene & rs number & $\begin{array}{l}\text { Allele } \\
\text { (major/ } \\
\text { minor) }\end{array}$ & $\begin{array}{l}\text { Homozygote } \\
\text { of protective } \\
\text { allele }\end{array}$ & Heterozygote & $\begin{array}{l}\text { Homozygote } \\
\text { of risk allele }\end{array}$ & $\begin{array}{l}p \text { value } \\
\text { (unadjusted) }\end{array}$ & $\begin{array}{l}p \text { value } \\
\text { (adjusted } \\
\text { for age } \\
\text { and } \mathrm{BMI} \text { ) }\end{array}$ \\
\hline \multirow[t]{18}{*}{ HOMA-IR } & \multirow[t]{2}{*}{$C D K A L 1$} & rs7756992 & $\mathrm{G} / \mathrm{A}$ & $3.18 \pm 2.17$ & $2.91 \pm 1.73$ & $2.81 \pm 1.62$ & 0.048 & 0.07 \\
\hline & & rs 7754840 & $\mathrm{C} / \mathrm{G}$ & $3.12 \pm 2.08$ & $2.94 \pm 1.75$ & $2.75 \pm 1.58$ & 0.029 & 0.049 \\
\hline & \multirow{4}{*}{$\begin{array}{l}C D K N 2 A / \\
2 B\end{array}$} & rs564398 & $\mathrm{T} / \mathrm{C}$ & $2.96 \pm 1.82$ & $2.85 \pm 1.65$ & $2.30 \pm 1.11$ & 0.15 & 0.79 \\
\hline & & rs 1333040 & $\mathrm{~T} / \mathrm{C}$ & $2.95 \pm 1.51$ & $2.95 \pm 2.07$ & $2.66 \pm 1.38$ & 0.29 & 0.98 \\
\hline & & rs 10757278 & $\mathrm{~A} / \mathrm{G}$ & $2.95 \pm 2.00$ & $2.83 \pm 1.75$ & $3.10 \pm 1.53$ & 0.51 & 0.96 \\
\hline & & rs 10811661 & $\mathrm{~T} / \mathrm{C}$ & $3.14 \pm 2.58$ & $2.87 \pm 1.64$ & $2.88 \pm 1.49$ & 0.26 & 0.15 \\
\hline & FTO & rs 8050136 & $\mathrm{C} / \mathrm{A}$ & $2.90 \pm 1.69$ & $2.98 \pm 1.97$ & $3.06 \pm 2.44$ & 0.53 & 0.73 \\
\hline & \multirow[t]{3}{*}{ HHEX } & rs1111875 & $\mathrm{T} / \mathrm{C}$ & $3.10 \pm 1.75$ & $2.81 \pm 1.86$ & $2.72 \pm 1.41$ & 0.017 & 0.026 \\
\hline & & rs5015480 & $\mathrm{T} / \mathrm{C}$ & $2.98 \pm 1.90$ & $2.80 \pm 1.55$ & $2.96 \pm 1.63$ & 0.29 & 0.12 \\
\hline & & rs7923837 & $\mathrm{A} / \mathrm{G}$ & $2.93 \pm 1.75$ & $2.88 \pm 1.83$ & $2.92 \pm 1.46$ & 0.80 & 0.42 \\
\hline & $I G F 2 B P 2$ & rs4402960 & $\mathrm{G} / \mathrm{T}$ & $2.94 \pm 1.64$ & $2.97 \pm 1.93$ & $2.60 \pm 1.51$ & 0.23 & 0.35 \\
\hline & SLC $30 A 8$ & rs 13266634 & $\mathrm{C} / \mathrm{T}$ & $2.95 \pm 1.46$ & $3.02 \pm 2.05$ & $2.78 \pm 1.53$ & 0.17 & 0.05 \\
\hline & \multirow[t]{2}{*}{$T C F 7 L 2$} & rs7903146 & $\mathrm{C} / \mathrm{T}$ & $2.93 \pm 1.77$ & $2.74 \pm 1.75$ & $3.57 \pm 3.17$ & 0.56 & 0.63 \\
\hline & & rs 12255372 & $\mathrm{G} / \mathrm{T}$ & $2.92 \pm 1.77$ & $2.62 \pm 1.36$ & NA & 0.66 & 0.44 \\
\hline & \multirow[t]{2}{*}{ KCNJ11 } & rs 5215 & $\mathrm{~A} / \mathrm{G}$ & $2.94 \pm 1.56$ & $3.00 \pm 2.04$ & $2.65 \pm 1.25$ & 0.25 & 0.59 \\
\hline & & rs 5219 & $\mathrm{G} / \mathrm{A}$ & $2.93 \pm 1.57$ & $2.96 \pm 2.02$ & $2.65 \pm 1.24$ & 0.23 & 0.53 \\
\hline & \multirow[t]{2}{*}{ PPARG } & rs3856806 & $\mathrm{C} / \mathrm{T}$ & $3.27 \pm 2.33$ & $2.91 \pm 1.74$ & $2.90 \pm 1.75$ & 0.50 & 0.84 \\
\hline & & rs1801282 & $\mathrm{C} / \mathrm{G}$ & 2.52 & $2.76 \pm 1.36$ & $2.93 \pm 1.81$ & 0.41 & 0.37 \\
\hline \multirow{18}{*}{$\begin{array}{l}\text { AUC of insulin during } \\
100 \mathrm{~g} \text { OGTT at the time } \\
\text { of diagnosis of GDM } \\
\left(\mathrm{pmol} 1^{-1} \times \mathrm{h}\right)\end{array}$} & \multirow[t]{2}{*}{$C D K A L 1$} & rs7756992 & $\mathrm{G} / \mathrm{A}$ & $1,573 \pm 956$ & $1,350 \pm 767$ & $1,287 \pm 756$ & 0.0012 & 0.0002 \\
\hline & & rs7754840 & $\mathrm{C} / \mathrm{G}$ & $1,555 \pm 926$ & $1,362 \pm 774$ & $1,248 \pm 743$ & 0.0001 & 0.00004 \\
\hline & \multirow{4}{*}{$\begin{array}{l}C D K N 2 A / \\
2 B\end{array}$} & rs564398 & $\mathrm{T} / \mathrm{C}$ & $1,355 \pm 800$ & $1,406 \pm 828$ & $1,222 \pm 585$ & 0.83 & 0.28 \\
\hline & & rs 1333040 & $\mathrm{~T} / \mathrm{C}$ & $1,391 \pm 797$ & $1,342 \pm 822$ & $1,333 \pm 738$ & 0.40 & 0.77 \\
\hline & & rs 10757278 & $\mathrm{~A} / \mathrm{G}$ & $1,380 \pm 736$ & $1,344 \pm 801$ & $1,378 \pm 924$ & 0.93 & 0.33 \\
\hline & & rs 10811661 & $\mathrm{~T} / \mathrm{C}$ & $1,530 \pm 991$ & $1,380 \pm 782$ & $1,275 \pm 727$ & 0.002 & 0.020 \\
\hline & FTO & rs 8050136 & $\mathrm{C} / \mathrm{A}$ & $1,317 \pm 772$ & $1,452 \pm 788$ & $2,000 \pm 1,745$ & 0.002 & 0.006 \\
\hline & \multirow[t]{3}{*}{ HHEX } & rs1111875 & $\mathrm{T} / \mathrm{C}$ & $1,530 \pm 897$ & $1,286 \pm 732$ & $1,106 \pm 600$ & 0.0000001 & 0.0000002 \\
\hline & & rs 5015480 & $\mathrm{~T} / \mathrm{C}$ & $1,458 \pm 846$ & $1,230 \pm 718$ & $1,158 \pm 631$ & 0.00005 & 0.0002 \\
\hline & & rs7923837 & $\mathrm{A} / \mathrm{G}$ & $1,423 \pm 833$ & $1,289 \pm 771$ & $1,234 \pm 652$ & 0.013 & 0.006 \\
\hline & $I G F 2 B P 2$ & rs 4402960 & $\mathrm{G} / \mathrm{T}$ & $1,378 \pm 826$ & $1,346 \pm 771$ & $1,373 \pm 819$ & 0.78 & 0.34 \\
\hline & SLC $30 A 8$ & rs 13266634 & $\mathrm{C} / \mathrm{T}$ & $1,419 \pm 758$ & $1,360 \pm 883$ & $1,337 \pm 728$ & 0.36 & 0.33 \\
\hline & \multirow[t]{2}{*}{$T C F 7 L 2$} & rs 7903146 & $\mathrm{C} / \mathrm{T}$ & $1,372 \pm 811$ & $1,255 \pm 684$ & $984 \pm 496$ & 0.21 & 0.08 \\
\hline & & rs 12255372 & $\mathrm{G} / \mathrm{T}$ & $1,361 \pm 798$ & $1,361 \pm 798$ & NA & 0.39 & 0.69 \\
\hline & \multirow[t]{2}{*}{ KCNJ11 } & rs 5215 & $\mathrm{~A} / \mathrm{G}$ & $1,378 \pm 786$ & $1,354 \pm 815$ & $1,347 \pm 806$ & 0.67 & 0.60 \\
\hline & & rs 5219 & $\mathrm{G} / \mathrm{A}$ & $1,383 \pm 795$ & $1,351 \pm 814$ & $1,350 \pm 799$ & 0.64 & 0.55 \\
\hline & \multirow[t]{2}{*}{ PPARG } & rs3856806 & $\mathrm{C} / \mathrm{T}$ & $1,270 \pm 671$ & $1,369 \pm 845$ & $1,364 \pm 791$ & 0.78 & 0.81 \\
\hline & & rs 1801282 & $\mathrm{C} / \mathrm{G}$ & 1,701 & $1,291 \pm 626$ & $1,368 \pm 816$ & 0.52 & 0.89 \\
\hline
\end{tabular}

Data are presented as mean $\pm \mathrm{SD}$

$p$ values were not corrected for multiple comparisons

NA, not available - no participants homozygous for the risk allele

CDKAL1 is expressed in human pancreatic islets and shows considerable homology with CDK5RAP1, a wellknown inhibitor of cyclin-dependent kinase 5 (CDK5) activation [23]. CDK5 has been suggested to downregulate insulin expression through the formation of $\mathrm{p} 35 / \mathrm{CDK} 5$ complexes [39, 40]. In addition, CDK5 transduces glucose toxicity signals in pancreatic beta cells [39].

The $5^{\prime}$ sequence upstream of rs 10811661 contains $C D K N 2 B$ and $C D K N 2 A$ (encoding $\mathrm{p} 15^{\mathrm{INK} 4 \mathrm{~b}}$ and $\mathrm{p} 16^{\mathrm{INK} 4 \mathrm{a}}$, respectively) [23]. p16 ${ }^{\mathrm{INK} 4 \mathrm{a}}$ is known to inhibit CDK4, a powerful regulator of pancreatic beta cell replication [41-44].
$C D K N 2 B$ overexpression was found to be related to islet hypoplasia and diabetes mellitus in murine models [45]. Furthermore, both $C D K N 2 A$ and $C D K N 2 B$ are expressed at high levels in pancreatic islets [23]. It was reported that the SNPs in this region showed a stronger signal as a haplotype [23], but we could not find such a trend in our study (ESM Tables 5 and 6)

In our study, the association of TCF7L2 with GDM was not as strong as that reported by the Scandinavian study [17]. This discrepancy may be explained by the difference in the frequency of the rs7903146 risk allele between the 
two studies (risk allele frequency in the control group was 0.238 vs 0.025 , respectively), even though the effect size was similar (OR $1.49,95 \%$ CI $1.28-1.75, p=4.9 \times 10^{-7}$ vs OR $1.58,95 \%$ CI $1.03-2.43, p=0.038$, respectively).

Although HHEX was not robustly associated with GDM, it was strongly associated with insulin secretory capacity. Interestingly, the protective allele of rs1111875 in HHEX was very modestly associated with increased insulin resistance (adjusted $p=0.026$ ) but very strongly associated with increased insulin secretory capacity (adjusted $p=0.0000002$ ). This finding suggests that rs 1111875 may be more likely to be one of the genetic factors involved in beta cell compensatory insulin secretion in the face of insulin resistance induced by pregnancy. It is known that HHEX is expressed at high levels in the fetal and adult pancreas [23] and is crucial for the development of the ventral pancreas [46]. In Europids [20-23], rs1111875 is found within an extended region of linkage disequilibrium that contains not only HHEX but also KIFI1 and IDE. Therefore, the influence of KIF11 and/or IDE cannot be ignored.

Although FTO did not show any significant association with GDM or insulin resistance, the risk allele of rs 8050136 in the FTO gene was found to be associated with an increased insulin AUC (age- and BMI-adjusted $p=0.006$ ). In addition, the pre-pregnancy BMI did not differ according to the rs8050136 genotype (data not shown). We suggest that rs 8050136 does not increase the risk of GDM but may afford protective by increasing insulin secretory capacity, at least in the Korean population.

We found that the risk allele frequencies of the SNPs in patients with GDM did not differ from those in patients with type 2 diabetes in the Korean population (Table 3). In this regard, some genetic factors (especially, rs7756992 and rs7754840 in CDKAL1 and rs10811661 in CDKN2A$C D K N 2 B)$ are associated with GDM in particular, as well as type 2 diabetes in general.

We recently confirmed that these SNPs were associated with the risk of type 2 diabetes in Koreans, showing similar effect sizes to those in Europeans, although the risk allele frequencies of most of these SNPs were different between populations [25]. The effect sizes of rs 7754840 and rs10811661 were slightly greater in Korean women with GDM than in Europeans with type 2 diabetes, although the effects were in the same direction.

This study is subject to certain limitations. We compared the genotype frequencies in GDM patients with those in non-pregnant, non-diabetic controls. The results of the current study may therefore be regarded as a comparison of genotype frequency among gene pools of patients with GDM and individuals with a very low risk of type 2 diabetes. A control group consisting of age- and BMImatched pregnant women without GDM may be more suitable for identification of the GDM susceptibility genes.
It was not confirmed whether the non-diabetic female controls who were enrolled in this study had experienced pregnancy without GDM. However, the ascertainment bias should be minimal because the prevalence of GDM is estimated to be very low ( 2.2 cases per 100 pregnant women in Korea) [3]. Our study was underpowered to detect associations of some of the SNPs with GDM (see ESM Table 2), probably because of their low frequencies, which may have resulted in some associations being overlooked.

In conclusion, some of the type 2 diabetes-associated genetic variants discovered in the recent GWA studies are also associated with GDM in Koreans. Further studies need to be conducted to examine whether these risk variants predict the development of type 2 diabetes later in life.

Acknowledgements This study was supported by a grant from the Korea Health 21 R\&D Project (Ministry of Health, Welfare and Family Affairs, Republic of Korea, no. 00-PJ3-PG6-GN07-001) and a Clinical Research Award from the Korean Diabetes Association.

Duality of interest The authors declare that there is no duality of interest associated with this manuscript.

\section{References}

1. Metzger BE (1991) Summary and recommendations of the Third International Workshop-Conference on Gestational Diabetes Mellitus. Diabetes 40(Suppl 2):197-201

2. Amankwah KS, Prentice RL, Fleury FJ (1977) The incidence of gestational diabetes. Obstet Gynecol 49:497-498

3. Jang HC, Cho NH, Jung KB, Oh KS, Dooley SL, Metzger BE (1995) Screening for gestational diabetes mellitus in Korea. Int J Gynaecol Obstet 51:115-122

4. Jovanovic L, Pettitt DJ (2001) Gestational diabetes mellitus. JAMA 286:2516-2518

5. McLellan JA, Barrow BA, Levy JC et al (1995) Prevalence of diabetes mellitus and impaired glucose tolerance in parents of women with gestational diabetes. Diabetologia 38:693-698

6. Martin AO, Simpson JL, Ober C, Freinkel N (1985) Frequency of diabetes mellitus in mothers of probands with gestational diabetes: possible maternal influence on the predisposition to gestational diabetes. Am J Obstet Gynecol 151:471-475

7. Buchanan TA, Xiang AH (2005) Gestational diabetes mellitus. J Clin Invest 115:485-491

8. Kim C, Newton KM, Knopp RH (2002) Gestational diabetes and the incidence of type 2 diabetes: a systematic review. Diabetes Care 25:1862-1868

9. O'Sullivan JB, Mahan CM (1964) Criteria for the oral glucose tolerance test in pregnancy. Diabetes 13:278-285

10. Robitaille J, Grant AM (2008) The genetics of gestational diabetes mellitus: evidence for relationship with type 2 diabetes mellitus. Genet Med 10:240-250

11. Zaidi FK, Wareham NJ, McCarthy MI et al (1997) Homozygosity for a common polymorphism in the islet-specific promoter of the glucokinase gene is associated with a reduced early insulin response to oral glucose in pregnant women. Diabet Med 14:228-234

12. Leipold H, Knofler M, Gruber C, Haslinger P, Bancher-Todesca D, Worda C (2004) Calpain-10 haplotype combination and association with gestational diabetes mellitus. Obstet Gynecol 103: $1235-1240$ 
13. Rissanen J, Markkanen A, Karkkainen P et al (2000) Sulfonylurea receptor 1 gene variants are associated with gestational diabetes and type 2 diabetes but not with altered secretion of insulin. Diabetes Care 23:70-73

14. Shaat N, Ekelund M, Lernmark A et al (2005) Association of the E23K polymorphism in the KCNJ11 gene with gestational diabetes mellitus. Diabetologia 48:2544-2551

15. Festa A, Krugluger W, Shnawa N, Hopmeier P, Haffner SM, Schernthaner G (1999) Trp64Arg polymorphism of the $\beta_{3^{-}}$ adrenergic receptor gene in pregnancy: association with mild gestational diabetes mellitus. J Clin Endocrinol Metab 84: 1695-1699

16. Leipold H, Knoefler M, Gruber C, Klein K, Haslinger P, Worda C (2006) Plasminogen activator inhibitor 1 gene polymorphism and gestational diabetes mellitus. Obstet Gynecol 107:651-656

17. Shaat N, Lernmark A, Karlsson E et al (2007) A variant in the transcription factor 7-like 2 (TCF7L2) gene is associated with an increased risk of gestational diabetes mellitus. Diabetologia 50:972-979

18. Watanabe RM, Allayee H, Xiang AH et al (2007) Transcription factor 7-like 2 (TCF7L2) is associated with gestational diabetes mellitus and interacts with adiposity to alter insulin secretion in Mexican Americans. Diabetes 56:1481-1485

19. Wellcome Trust Case Control Consortium (2007) Genome-wide association study of 14,000 cases of seven common diseases and 3,000 shared controls. Nature 447:661-678

20. Saxena R, Voight BF, Lyssenko V et al (2007) Genome-wide association analysis identifies loci for type 2 diabetes and triglyceride levels. Science 316:1331-1336

21. Scott LJ, Mohlke KL, Bonnycastle LL et al (2007) A genomewide association study of type 2 diabetes in Finns detects multiple susceptibility variants. Science 316:1341-1345

22. Sladek R, Rocheleau G, Rung J et al (2007) A genome-wide association study identifies novel risk loci for type 2 diabetes. Nature 445:881-885

23. Zeggini E, Weedon MN, Lindgren CM et al (2007) Replication of genome-wide association signals in UK samples reveals risk loci for type 2 diabetes. Science 316:1336-1341

24. Frayling TM (2007) Genome-wide association studies provide new insights into type 2 diabetes aetiology. Nat Rev Genet 8:657662

25. Ng MC, Park KS, Oh B et al (2008) Implication of genetic variants near TCF7L2, SLC30A8, HHEX, CDKAL1, CDKN2A/B, $I G F 2 B P 2$ and $F T O$ in type 2 diabetes and obesity in 6,719 Asians. Diabetes 57:2226-2233

26. Jang HC, Cho NH, Min YK, Han IK, Jung KB, Metzger BE (1997) Increased macrosomia and perinatal morbidity independent of maternal obesity and advanced age in Korean women with GDM. Diabetes Care 20:1582-1588

27. Matthews DR, Hosker JP, Rudenski AS, Naylor BA, Treacher DF, Turner RC (1985) Homeostasis model assessment: insulin resistance and beta-cell function from fasting plasma glucose and insulin concentrations in man. Diabetologia 28:412-419

28. Helgadottir A, Thorleifsson G, Manolescu A et al (2007) A common variant on chromosome $9 \mathrm{p} 21$ affects the risk of myocardial infarction. Science 316:1491-1493

29. McPherson R, Pertsemlidis A, Kavaslar N et al (2007) A common allele on chromosome 9 associated with coronary heart disease. Science 316:1488-1491
30. Samani NJ, Erdmann J, Hall AS et al (2007) Genomewide association analysis of coronary artery disease. N Engl J Med 357:443-453

31. Grant SF, Thorleifsson G, Reynisdottir I et al (2006) Variant of transcription factor 7-like 2 (TCF7L2) gene confers risk of type 2 diabetes. Nat Genet 38:320-323

32. Koo BK, Cho YM, Park BL et al (2007) Polymorphisms of KCNJ11 (Kir6.2 gene) are associated with type 2 diabetes and hypertension in the Korean population. Diabet Med 24:178-186

33. Moon MK, Cho YM, Jung HS et al (2005) Genetic polymorphisms in peroxisome proliferator-activated receptor gamma are associated with type 2 diabetes mellitus and obesity in the Korean population. Diabet Med 22:1161-1166

34. Horikoshi M, Hara K, Ito C et al (2007) Variations in the HHEX gene are associated with increased risk of type 2 diabetes in the Japanese population. Diabetologia 50:2461-2466

35. Karnik SK, Chen H, McLean GW et al (2007) Menin controls growth of pancreatic beta-cells in pregnant mice and promotes gestational diabetes mellitus. Science 318:806-809

36. Buchanan TA (2001) Pancreatic B-cell defects in gestational diabetes: implications for the pathogenesis and prevention of type 2 diabetes. J Clin Endocrinol Metab 86:989-993

37. Kautzky-Willer A, Prager R, Waldhausl W et al (1997) Pronounced insulin resistance and inadequate beta-cell secretion characterize lean gestational diabetes during and after pregnancy. Diabetes Care 20:1717-1723

38. Ryan EA, Imes S, Liu D et al (1995) Defects in insulin secretion and action in women with a history of gestational diabetes. Diabetes 44:506-512

39. Ubeda M, Rukstalis JM, Habener JF (2006) Inhibition of cyclindependent kinase 5 activity protects pancreatic beta cells from glucotoxicity. J Biol Chem 281:28858-28864

40. Wei FY, Nagashima K, Ohshima T et al (2005) Cdk5-dependent regulation of glucose-stimulated insulin secretion. Nat Med 11:1104-1108

41. Krishnamurthy J, Ramsey MR, Ligon KL et al (2006) p16INK4a induces an age-dependent decline in islet regenerative potential. Nature 443:453-457

42. Marzo N, Mora C, Fabregat ME et al (2004) Pancreatic islets from cyclin-dependent kinase 4/R24C (Cdk4) knockin mice have significantly increased beta cell mass and are physiologically functional, indicating that $\mathrm{Cdk} 4$ is a potential target for pancreatic beta cell mass regeneration in type 1 diabetes. Diabetologia 47:686-694

43. Mettus RV, Rane SG (2003) Characterization of the abnormal pancreatic development, reduced growth and infertility in Cdk4 mutant mice. Oncogene 22:8413-8421

44. Rane SG, Dubus P, Mettus RV et al (1999) Loss of Cdk4 expression causes insulin-deficient diabetes and Cdk4 activation results in $\beta$-islet cell hyperplasia. Nat Genet 22:44-52

45. Moritani M, Yamasaki S, Kagami M et al (2005) Hypoplasia of endocrine and exocrine pancreas in homozygous transgenic TGF-ß1. Mol Cell Endocrinol 229:175-184

46. Bort R, Martinez-Barbera JP, Beddington RS, Zaret KS (2004) Hex homeobox gene-dependent tissue positioning is required for organogenesis of the ventral pancreas. Development 131:797-806

47. Steinthorsdottir V, Thorleifsson G, Reynisdottir I et al (2007) A variant in $C D K A L 1$ influences insulin response and risk of type 2 diabetes. Nat Genet 39:770-775 